\section{ANALES DEL INSTITUTO DE INVESTIGACIONES ESTETICAS}

Anales del Instituto de Investigaciones

\section{Estéticas}

ISSN: 0185-1276

iieanales@gmail.com

Instituto de Investigaciones Estéticas

México

Báez RUBí, Linda

De harmonia mundi: ¿Un reino de Saturno novohispano?

Anales del Instituto de Investigaciones Estéticas, vol. XX, núm. 73, otoño, 1998, pp. 41-67

Instituto de Investigaciones Estéticas

Distrito Federal, México

Disponible en: http://www.redalyc.org/articulo.oa?id=36907302

- Cómo citar el artículo

- Número completo

- Más información del artículo

- Página de la revista en redalyc.org

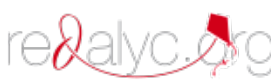

Sistema de Información Científica

Red de Revistas Científicas de América Latina, el Caribe, España y Portugal Proyecto académico sin fines de lucro, desarrollado bajo la iniciativa de acceso abierto 


\title{
De harmonia mundi: ¿Un reino de Saturno novohispano?*
}

\author{
In memoriam \\ Elda Aída Rubí de Báez (I939-1994) \\ Al reino de los $\mathrm{H}$ ijos del alba
}

Fax it tamen ut cumque D eus, ut fiat in terris sicut in caelis ipsius voluntas. U t iam redeat et virgo: redeant saturnia regna.

Iam nova progenies: caelo mittantur ab alto. Pax sit et in toto surgat concordia mundo.

C arolus Bovillus a Francisco Ximénez de Cisneros, 2o de marzo de i509, Epistole complures, 0 pera omnia, f. I75r.

\begin{abstract}
Ciempre que tocamos el tema del neoplatonismo renacentista, se nos presenta un campo de investigación en cuya variedad yace la fascinación, en cuyas infinitas analogías yacen un sinfín de interpretaciones. Es obvio, el simple hecho de pensar en que hay que enfrentar concepciones tan delicadas como el hermetismo, la magia, la teúrgia, el cabalismo cristiano, el profetismo, el pitagorismo, la mnemotecnia, nos pone en un verdadero

*Agradezco a la biblioteca del W arburg Institute por la valiosa información que me ha aportado, así como al apoyo de la Konrad Adenauer Stiftung, a la maestra E. Gerlero, a la doctora A. M uñiz, al maestro E. Báez, G. M inauro y A. Estrada.
\end{abstract}


predicamento. ${ }^{\mathrm{I}}$ Son, indudablemente, vías de pensamiento que muchas de las veces van íntimamente entrelazadas, y es difícil delinear sus límites para comprender fríamente cómo se manifiestan en la realidad. Estamos, en pocas palabras, a merced de una locura interpretativa. Sin embargo, algo nos puede guiar en esta madeja cosmológica: el enfocarnos a un solo tema, en este caso al amor.

$M$ arsilio Ficino (I433-I499), ${ }^{2}$ médico y humanista erudito fue encomendado por Lorenzo de M édicis para traducir el corpus, no sólo de las obras de Platón (I463-I469), sino también el hermético. Posteriormente, desarrollaría sus propias obras D e religione Christiana (I474), Theologia Platonica (I476), Triplici vita (I489), ${ }^{3}$ bajo las influencias de estas corrientes. ${ }^{4}$ Algunos de los temas que mencioné al principio formaron parte de su sistema ideológico. $M$ ás allá aún, Ficino legaría ideas fundamentales a la época renacentista conformada por personajes de la talla de Pico della M irandola, Johannes Reuchlin, etc.5 Pero volvamos al tema central, ¿cuál era la concepción del amor del neoplatonismo que inició Ficino? A lo largo del corpus ficiniano, se exponen conceptos que caracterizan su pensamiento: el amor, la belleza, la armonía, el orden: todas ideas aplicables no solamente al universo y a la creación, sino al hombre mismo. ${ }^{6} \mathrm{Si}$ recordamos la teoría neoplatónica de las almas, podremos vislumbrar una idea central: la restitución del alma a la unidad suprema, después de su desprendimiento o caída del plano divino al mundo sublunar atravesando el plano celestial.7 La tarea del hombre cristiano es

I. Para este contexto, véase F. A. Yates, The 0 ccult Philosophy in the Elizabethan Age, Londres, Routledge and K. Paul, i974.

2. Para las posturas filosóficas de Ficino, véase $O$ skar Kristeller, Philosophy of $M$ arsilio Ficino, N ueva York, Columbia U niversity Press, 1943.

3. Estas obras compiladas en M arsilio Ficino, O pera omnia, Basilea, 1576 (ed. facsimilar de 0 . Kristeller), 2 vols., Turín, Bottega d'E rasmo, 1962.

4. Para un estudio de las corrientes hermético-neoplatónicas en Ficino, véase Cesare Vasoli, Ficino and Renaissance N eoplatonism (eds. K onrad Eisenbichler, O Iga Pugliese), Toronto, D ovenhouse Editions, I986; D. P. W alker, The Ancient Theology. Studies in Christian Platonism from the Fifteenth to the Eighteenth Century, Londres, D uckworth, 1972.

5. Cfr. D. P. Walker, Spiritual and D emonic M agic from Ficino to Campanella, Londres, The W arburg Institute U niversity of L ondon, 1958.

6. Para una explicación sobre estos temas principales y su vinculación, véase Eugenio G arin, I talian H umanism. Philosophy and Civic Life in the Renaissance, pp. 98-99.

7. La explicación de este tema neoplatónico en relación con las teorías de Ficino y el papel que juega el amor bajo el rubro de "furor divino" en este marco filosófico-religioso, véase J. Féstugiere, La philosophie de l'amour de M arsile Fi cin et son influence sur la littérature française au xvie siècle, pp. 22-25. 
pues, bajo la influencia neoplatónica, elevar el alma hacia Dios: ascender de nueva cuenta a través del universo y las órbitas estelares, proceso en el cual se lleva cabo la purificación interna. ${ }^{8}$ Este último acto, bajo la mirada del neoplatonismo cristianizado, implica el ejercicio de un sistema de valores específico plagado de virtudes cristianas para que el alma humana sea capaz de desarrollar un código de conducta correcta, noble, buena, puesto que el fin es la suma bondad misma, o sea Dios. Él es expresión, así, de la máxima belleza, atributo que se liga directamente con la concepción estética de Ficino.9 Para el neoplatónico cristiano, la estética reside no sólo en la correspondencia de todas las partes del universo que logran conjuntar una visión armónica sino, por principio, en el hombre mismo. ${ }^{\circ 0} \mathrm{El}$ hombre como microcosmos refleja esa unidad equilibrada sobre la que descansa la estructura del macrocosmos. ${ }^{\text {II }}$ A hora bien, lo importante es detectar qué es lo que genera en el hombre el apetito por la belleza, qué es lo que le impulsa a desarrollar una ética y crear una estética, y esto es clara y principalmente el impulso amoroso. ${ }^{{ }^{2}}$ Efectivamente, el amor neoplatónico-cristiano es capaz de componer el edifico armónico del mundo donde todas las partes se corresponden en el orden divino. ${ }^{\mathrm{I3}}$

Ahora bien, este edificio que traduce su perfección en términos musicales y matemáticos pone énfasis en el orden del mundo. Bajo el orden, Ficino vislumbra y organiza la estructura del cielo y la jerarquía de los seres, cuya autoría atribuye al supremo arquitecto: $\mathrm{D}$ ios. ${ }^{14} \mathrm{H}$ ay que enfatizar que, cuando hablamos de este edifico armónico, hablamos también de las esferas

8. Para la explicación de este proceso, véase M arsilio Ficino, Commentary on Plato's Symposium on Love, oratio VI, pp. IO7-I52.

9. André Chastel, M arsile Ficine et l'art, p. 57.

Io. "Tandem partes mundi cunctae ad unim quedam totius mundi decorem ita concurrunt ut nihil substrahi possit, nihil addi", M arsilio Ficino, Theologia Platonica, vol. II, libro 2, cap. I3, p. 2 I2.

II. Esta idea la repiten varios neoplatónicos, como Pico della M irandola, para el que "la realidad se constituye de diferentes niveles; sin embargo, ellos se corresponden entre sí y se hallan relacionados, así como también se hallan en el hombre, puesto que él participa de todos ellos". Eugenio Garin, Italian H umanism, p. Io7.

I2. Cfr. Féstugiere, La philosophie de l'amour de M arsileFicin, p. 32.

I3. "Ita mundi totius ordinem esse in D eo, uno tantum principe mundi. Proinde partes mundi et copuscula quaelibet ad certum finem per viam ordinatissimam." M arsilii Ficini Florentinii, Theologia platonica, vol. II , libro 2, cap. XIII, p. 202.

I4. I bidem, p. I20. 
celestes que lo conforman, y en las cuales residen los planetas según el sistema ptolemaico tan caro a los neoplatónicos. El movimiento de las estrellas depende de leyes matemáticas, es decir divinas, que marcan su recorrido en esa estructura de equilibrio perfecto y que influyen al hombre. ${ }^{15}$ Precisamente bajo este marco, hay que entender lo que Ficino quería decir cuando se refería al número fatal, también Ilamado número nupcial. ${ }^{16}$ Este número representaba el tiempo que le tomaba a cada planeta el regresar al lugar de inicio desde el cual había comenzado a recorrer su órbita: es cuando la historia completa su círculo y comienza un nuevo ciclo. ${ }^{17}$ Este recorrido celestial está ligado estrechamente con el hombre, es decir que el hombre tiene la posibilidad de regresar a su condición primera, lo que en cuestiones más prácticas significa su regeneración. ${ }^{18}$

Es importante reconocer esta idea medular neoplatónica, puesto que de aquí se va a desprender la mayor parte de la explicación del porqué, dentro del Renacimiento, el sentido profético cobra un nuevo auge y una especial atención.19

II

N on potest coelum eius rei signum esse, cuius causa non sit. Pico della M irandola, In astrologiam, libro 4, cap. xII, f. 543.

Si bien el tema de la astrología es un tema espinoso, los conocedores han

I5. "Q uoniam vero coelum est harmonica ratione compositum moveturque harmonice... merito per harmoniam solam non solum homines, sed inferiora haec omnia pro viribus ad capienda coelestia praeparantur." M arsilio Ficino, D e vita triplici, III, 22, O pera, p. 565.

I6. "N on solum vero dispositiones corporum omnino sed quodammodo etiam affectuum ingeniorumque et morum varietates fatali hac et naturali quadam lege ducuntur. Proveniunt vero quibusdam secullis divina quaedam ingenia potiusquam humana, producta videlicet conversionibus revolutioibusque soli D eo certis atque destinatis." M arsilio Ficino, Commentaris in locum Platonis ex octavo Libro de Re Publica de M utatione Rei Publicae per N umerum Fatalem, cap. I, p. 173.

17. "Principio ciclos, id est, circos vel circulos, nominat substantias ipsas mundanarum sphaerarum, praecipue vero celestium. A pellat deinde peritropas, id est, conversiones, motus simpliciter circulares quos sphaerae caelestes et stellae quaelibet quasi fixae peragunt circa propria centra." I bidem, libro 2, cap. XIII, p. 173.

I8. M ichel J. B. Allen, N uptial A rithmetic, p. I3.

I9.U n texto que puede servir de manifiesto a la relación entre profecía y la influencia de las 
logrado dilucidar algo fundamental: la controversia acerca de una astrología determinativa o simplemente con un carácter influyente; esta última se distingue por no ser decisiva sobre el curso de la vida del hombre. ${ }^{20} \mathrm{La}$ astrología medieval, por decirlo así, estaba plagada de demonios astrales que infundían temor al hombre porque podían actuar sobre él..$^{2 r} \mathrm{D}$ urante el Renacimiento ocurrió un fenómeno vital para la relación del hombre con el universo. Si bien el hombre formaba parte de esa arquitectura universal y ocupaba, por lo tanto, un lugar en la jerarquía del mundo, entonces era capaz de movilizarse a través de los distintos planos y niveles en los que se dividía el mundo. ${ }^{22}$ Precisamente gracias al impulso amoroso que lo hacía moverse hacia la suprema belleza, es decir hacia $D$ ios, es lo que lo dotaba de una fuerza interna (voluntad) que se manifestaba en la elaboración de una ética sólida basada en la actividad de las virtudes más sublimes. Y esto es lo que el segundo gran manifiesto neoplátonico nos deja entrever: la D e dignitate hominis de Pico della M irandola. ${ }^{23}$ Este modelo permeó todo el pensamiento renacentista, además de que determinó indudablemente la posición del hombre ante el pensamiento astrológico: el ser humano no estaba ante demonios astrales, puesto que las estrellas son simplemente cuerpos celestes que se mueven por leyes matemáticas, divinas y armónicas, lejos de estar habitadas por entes demoniacos. ${ }^{24}$ En segundo lugar, si bien el hombre recibía la influencia de los astros, era capaz de manejar esa influencia según su libre

leyes que operan en los cuerpos celestiales aplicadas a los acontecimientos históricos, así como de receptor de las ideas de Ficino, Pico y Savonarola, es el de Giovanni N essi, O raculum de novo saeculo, Florencia, I496. La edición de este texto se puede consultar en C esare Vasoli, "L 'hermétisme dans I'O raculum de Giovanni N essi", Cahiers de I'H ermétisme. Présence d'H ermèsT rismégi ste, París, Albin M ichel, 1988, pp. I53-166.

20. Para la continuidad y cambio de la astrología medieval en el Renacimiento, véase Aby W arburg, "H eidnisch-antike W eissagung in W ort und Bild zu Luthers Zeiten", Ausgewählte Schriften und Würdigungen (ed. D ieter Wuttke), za. ed., Baden-Baden, Verlag Valentin Lierner (C olección Saecula Spiritualia), 1980, pp. 478-558.

2I. The Latin Version of the G hayat al-hakim (ed. D avid Pingree), Londres, The Warburg Institute, 1986.

22. Para una exégesis sobre el sentido ascensional y descensional de Pico della M irandola, véase $\mathrm{E}$. Garin, Giovanni Pico della M irandola. Vita edottrina, pp. 209-213.

23. Pico della M irandola, D e hominis dignitate, Heptaplus, de ente et uno, véase (ed. E. Garin), Florencia, Vallecchi Editore, 1992.

24. Cassirer, Individuum und Kosmos in der Philosophie der Renaissance, Leipzig-Berlín, B. G. Teubner, 1927, p. I24. 
albedrío y su voluntad. ${ }^{25} \mathrm{~N}$ ecesario es entender que, dentro de la concepción renacentista, el hombre es libre de la determinación astral, de un destino fijo e irrevocable, y que en él mismo reside el poder de manejar esas fuerzas ocultas de la naturaleza para su propio beneficio y desarrollo interno. Esto es la explicación del porqué muchos magos renacentistas se oponían al tipo de astrología medieval determinista: simplemente, admitirla representaba una contradicción para el punto medular de la teoría neoplatónica que situaba al hombre como microcosmos y capaz de crear su destino como fiel reflejo de un ser divino.

Prioritario era entender esta aclaración sobre la astrología y la magia en el Renacimiento, para entender e interpretar correctamente a aquellos que atribuyeron, como Ficino, un papel importante a las profecías, pero que desecharon la demonología astral a favor tan sólo de una influencia de los cuerpos celestiales en el mundo sublunar, influencia que el ser humanomago podría dominar conociendo sus leyes. El famoso Girolamo Savonarola desencadenaría con su mensaje de renovatio humana en el plano religioso, una gran cauda de ambiente profético. ${ }^{26}$ En él la idea predominante era el vislumbramiento de una edad áurea, pacífica, unida bajo un solo rebaño cristiano, y que probablemente se daría cuando el sol entrara en la casa del signo zodiacal de Aries. ${ }^{27}$ Los mismos sucesos políticos dieron auge y valor a las profecías que se ligaban con las revoluciones estelares y que, lejos de estar desconectadas de los intereses político-religiosos, eran una forma de legitimar las aspiraciones de poder de ciertos sectores dentro de la vida político-religiosa. ${ }^{28} \mathrm{Si}$ bien Savonarola veía con cierto escepticismo el sincretismo religioso de Ficino, ${ }^{29}$ no distaba de concordar con las posiciones de Pico y Ficino sobre la renovación de una religiosidad laica en el hombre. Las constantes invasiones y amenazas bélicas, causadas por la ambición expansionista en

25. "D ebido a que el hombre sabio no puede librarse de la fuerza de su signo planetario, solamente le queda dirigir la fuerza hacia el bien, y esto lo logra reuniendo las influencias benéficas en sí mismo que se desprenden de los cuerpos celestes, fortaleciéndose internamente, y así, desviando las influencias negativas." C assirer, Indi viduum und Kosmos, p. ro6.

26. Para este tema, cfr. D onald W einstein, Savonarola and Florence. Prophecy and Patriotism in the Renaissance, Princeton, Princeton U niversity Press, 1970.

27. D. P. W alker, The Ancient Theology, p. 55.

28. Cesare Vasoli, Civitas mundi. Studi sulla cultura del cinquecento, p. I7.

29. Savonarola ataca a Platón y Aristóteles en dos sermones: sobre Ezequiel xv, recitado en

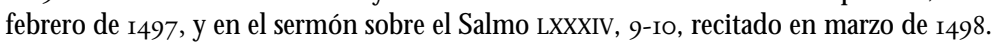


Europa, generaron, principalmente en la península itálica, un clima donde los sucesos correspondían a castigos divinos sufridos por la corrupción moral. ${ }^{30}$ Sin embargo, después se esperaría la regeneración. El proceso de purificación veía en las profecías religiosas su mejor expresión social-psicológica: lo importante era la regeneración después de los castigos de $D$ ios. En este sentido, los humanistas no estaban lejos de otorgarle este tipo de valor regenerador al mensaje profético, que era expresión, en realidad, de un profundo sentido político-religioso. ${ }^{3 \mathrm{I}} \mathrm{L}$ a estela de pensamiento savonaroliano que vislumbraba una espiritualidad regenerada de sus vicios, se unía al ánimo de establecer la pax christiana, la armonía del universo bajo la bandera de la cristiandad.

Sub Saturno natii ut optimi aut pessimi.

C arolus Bovillus, Proverbiorum vulgarium libri tres, f. rogr.

Charles de Bovelles,,$^{32}$ discípulo del gran reformista francés Lefèvre d'Etaples, ${ }^{33}$ representa mucho para nuestra cultura novohispana. Ambos nombres se asocian con el nacimiento del humanismo francés a finales y principios del siglo xvi. ${ }^{34} \mathrm{El}$ renacimiento neoplatónico que propuso el círculo de colaboradores de Lefèvre fue principalmente el rescate de la mística medieval con

30. En I494, Italia era invadida por la armada francesa de C arlos VIII, hecho que se conjuntó con la decadencia medicea y generó una atmósfera de pesimismo dentro del ambiente florentino. La situación de la I glesia distaba de presentar un panorama mejor: la corrupción y el abuso de sus dirigentes causaba el escándalo por toda Europa, donde los cristianos clamaban por tiempos mejores. C fr. Cesare Vasoli, "Profezie e Profeti nella vita religiosa e politica fiorentina", en M agia, astrologia e religione nel rinascimento, Varsovia, Academia Polacca delle Scienze, 1972, pp. 19-23.

3i. Para una explicación de la relación entre política, hecho histórico y el surgimiento de la profecía que los contiene, véase Arnaldo M omigliano, "From the Pagan to the Christian Sybil: Prophecy as H istory of Religion", The U ses of Greek and Latin (eds. A. C. D ionisotti, A. Grafton, J. K raye), Londres, The W arburg Institute, I988, pp. 3-17.

32. Para el estudio de su vida y obra, véase Joseph M. Victor, Charles de Bouvelles ( 1479 153). An Intellectual Biography, Génova, Libraire D rosz, 1978.

33. Sobre su vida y obra, véase Augustin Renaudet, H umanismeet Renaissance, pp. 20I-2I2.

34. Para este tema véase Augustin Renaudet, Préréforme et $\mathrm{H}$ umanisme à Paris (I494-ISI7), $2 \mathrm{a}$. ed., G énova, Slatkine Reprints, I953. 
afinidad neoplatónica, y un aristotelismo visto bajo un prisma, asimismo, neoplatónico. En estas directrices cabe mencionar lo que es de sobra conocido para algunos: el renacimiento del ars del Doctor Iluminado Ramón Llull.35 C reo que los temas lulistas cobraron auge porque la misma época que mediaba entre los desastres y castigos divinos, así como la esperanza del restablecimiento de una edad de oro evangélica, buscaban ideales que llenaran las expectativas: los modelos místicos, la piedad cristiana laica, el eremitismo, en fin, un tono más evangélico y sencillo en donde se uniera la cristiandad finalmente al lograr la conversión de los infieles. ${ }^{36}$ Es así como Bouvelles se involucra en esta ideología que se deja ver cuando pone sus esperanzas en la renovación de la Iglesia en manos del gran cardenal reformador de la espiritualidad hispánica, Francisco Jiménez de Cisneros. El hecho de que el cardenal toledano haya emprendido la reforma de las órdenes regulares y su triunfo en 0 rán contra los infieles Ilenaban los ánimos encendidos por el anhelo de renovación a la vez que daban respuesta al sentimiento profético que flotaba en el ambiente mesiánico religioso. ${ }^{37}$ La conversión de los infieles se sentía cerca, cuando no ya vuelta predicción, para fechas aproximadas; la recuperación de la Tierra Santa se convertía en una esperanza sólida, y con ella la unidad de la I glesia se vislumbraba a la mano. Así fue como la relación entre Cisneros y Charles de Bouvelles se basó en un esfuerzo en común: la unidad religiosa de la I glesia cristiana bajo la égida de la restitutio de una espiritualidad más evangélica. ${ }^{38}$ En este sentido es

35. Sobre Llull, remito al lector a los estudios de los hermanos Carreras y Artau, $\mathrm{H}$ istoria de la filosofía española de los siglos XIII al XV, 2 vols., M adrid, Real Academia de Ciencias Exactas, Físicas y N aturales, 1943.

36. En general, para este ambiente, véase $M$ arcel Bataillon, Erasmo y España. Estudios sobre la historia espiritual del siglo XVI (tr. Antonio Alatorre), za. ed., M éxico, Fondo de Cultura Económica, 1966. No trata a Llull suficientemente, sin embargo da pistas importantes de la posible influencia del beato en la reforma cisneriana.

37. "H oc profecto veri pastoris et officium... volentes ac suapte natura aberrantes homines cogere ut nuptiales eterni sponsi thalamos etiam inuiti et iuxta Scripturam a ministris compulsi subintrent". Carolus Bovillus a Fco. Ximénez de Cisneros, 22 de agosto de 1509 , Epistolae, O pera omnia, f. I74V.

38. "Aliqua similia his phantasiis en dicam deliramentis que $\mathrm{C}$ arolus Bovillus dicere solebat de reformatione scilicet ecclesie in brevi futura et de multis mirabilibus cito eventuris et quod $\mathrm{H}$ ierusalem totusque terre orbis cito esse venturus in cognitionem fidei et in deditionem christianorum et quod viros spirituales apostolicos et mirabiles $D$ eus esset cito excitaturos et missurus ad mirificam reformationem ecclesie sue." Juan de Cazala al cardenal C isneros, I512, cit. por J. M. Victor, Charles de Bovelles (I479-I553), p. I6, nota 29. 
como Bouvelles reconoce vislumbrar la influencia de los fenómenos celestes en el hombre: el retorno del reino de Saturno, bajo el cual el hombre por voluntad propia podía encaminar esos influjos hacia el bien, la belleza suprema, generada por el amor, o hacia su polo opuesto: el mal, la destrucción, el pecado. ${ }^{39}$ Si bien la imagen de Saturno en la Edad M edia se vinculaba con las catástrofes y el sentido apocalíptico, en el Renacimiento, gracias a la conciencia del hombre de su libertad y voluntad, Saturno adquiere el carácter positivo clásico que poseía, al vinculársele con la Edad de $\mathrm{O}$ ro descrita por H esíodo, H omero y Virgilio.40 Es así como, para los neoplátonicos, el reino de Saturno aparece como señor de las revoluciones a través de los sucesos catastróficos, pero para preparar una mejor época. ${ }^{41}$

Bouvelles distaba mucho de ser un simple teórico. La edición de las Contemplationes de Llull y el camino de contemplación mística que exponía esta obra le sirvieron como modelo a tal grado que se alejó por un tiempo a practicar la vida en soledad, eremítica, para encerrarse en la vida contemplativa. ${ }^{22} \mathrm{D}$ e ahí que haya trabado no sólo amistad con Cisneros, sino concordado con la visión de una reforma monástica urgente sobre la cual erigir la nueva sociedad cristiana.

Pero las preguntas fundamentales, una vez delineadas las directrices del pensamiento de los humanistas cristiano-renacentistas, son ¿en qué medida se aplicó este proyecto a una realidad más allá de la experiencia personal, extracontinental, y cuál fue en dado caso su realidad? ¿Fue algo práctico, 0 se quedó simplemente con el rubro de utópico? ¿Q uiénes conformarían el "reino de los hijos de Saturno" del que Bouvelles le hablaba a Cisneros?

39. Ficino, D e vita triplici, III, 2, O pera, p. 533: "Saturnos non facile communem significat humani generis qualitatem atque sortem, sed hominem ab aliis segregatum, divinum aut brutum, beatum aut extrema miseria pressum."

40. C fr. Platón, Las Leyes, IV, 713C-714a. En este pasaje, Kronos aparece "como amigo de la humanidad, bajo él prevalece el orden, la ley; es la era del nous, es el arquitecto del mundo". Raymond Klibansky, Erwin Panofsky, Fritz Saxl, Saturno y la melancolía, p. i63.

4I. André Chastel, "Le mythe de Saturne dans la Renaissance italienne", en Phoebus, I (1946), p. I32.

42. C fr. este testimonio ligado con el deseo de Lefèvre de abandonar el mundo material en la introducción al Primum volumen contemplationem raemundi, f. IV. 
La providencia divina tenga ordenado en su mundo: que para dirección y común utilidad el linaje humano se constituyesen en los Reynos y pueblos, reyes, como padres y pastores (según los nombra $\mathrm{H}$ omero) y por consiguiente sean los más nobles y generosos miembros de las repúblicas: ninguna dubda de la rectitud de sus ánimos reales se tiene o con recta razón se debe tener: que si algunos defectos y males se padecen en ellas: no ser otra la causa sino carecer los reyes de la noticia de ellos...

Fray Bartolomé de las $C$ asas, B revísima relación dela destrucción de Indias, sig. a 2 r.

En un estudio de enorme utilidad, ${ }^{43}$ se menciona que en inventario de la biblioteca del primer arzobispo de M éxico, fray Juan de Zumárraga, había una obra de $\mathrm{C}$ arolo Bovillo, que se presume fue el Commentarius in primordiale Evangelium (París, Josse Bade, I5II). Esta obra posee tres significados importantes: el primero es que una obra de Bouvelles aparezca en la biblioteca de un arzobispo-misionero franciscano en la N ueva España, quien obviamente planeó el proyecto de evangelización junto con M otolinía, fray Pedro de $G$ ante y Bartolomé de las $C$ asas, entre otros. El segundo radica en que es una obra que se publicó junto con una versión de la vida de Ramón Llull,44 de hecho fue la primera versión impresa. En ella, Bouvelles se dedica a resaltar el carácter ascético y místico de Llull, es decir, pone de relieve el ejemplo de la vida monástica del D octor Iluminado, sus ideas de conversión pacífica y la unidad de las ciencias en el universo. El tercer significado reside en la estructura del Comentario, y la relación que guarda esta estructura con otra obra de Bouvelles escrita casi simultáneamente, ambas aparecidas en I5Ir: la Dominica oratio tretrinis ecclesiasticae hierarchiae ordinibus. El texto

43. Ildefonso Adeva-C armen J. Alejos, "Fuentes de inspiración de la Regla cristiana breve de Fr. Juan de Zumárraga, O FM ", Archivvum Franciscanum H istoricum, 85 (1992), pp. 77-98.

44. La epístola la publicó J. M. Victor, "Charles de Bouvelles and N icholas de Pax: T wo Sixteenth-C entury Biographies of Ramon Lull", Traditio, XxXII (I976), pp. 313-345. 
del Comentarius se desglosa en varios fragmentos, ${ }^{45}$ procedimiento que aparece en la D ominica oratio y que más adelante analizaremos. Por ahora, bástenos subrayar la presencia de Bouvelles y con ella el conocimiento de Llull y sus obras (puesto que Bouvelles incluye en la biografía una lista de las obras del Beato) en el bagaje ideológico misional de la Nueva España, heredero de la reformas cisnerianas. Esta aseveración parecería muy débil y apresurada, sobre todo si lo que intento es ratificar la influencia del pensamiento de Llull (bajo el marco neoplatónico de la renovatio-concordia al estilo de Bouvelles) en algunos aspectos del programa de evangelización novohispana. Es cierto, pero tenemos otra pista importante.

Fray Toribio de Benavente M otolinía en su Historia de los indios de la N ueva España (ca. I54I), realiza una descripción valiosa para los actuales historiadores del arte novohispano: me refiero a las pinturas de la capilla abierta de Belén, pintadas para las fiestas de Corpus Christi en T laxcala, en el año de I539:

Ilámanla Belén, por parte de afuera la pintaron luego a el fresco en cuatro días...; en un ochavo de ella pintaron las obras de la creación del mundo...; en otros dos ochavos, en el uno la verga de Jesé, con la generación de la M adre de D ios, la cual está en lo alto puesta muy hermosa... en otra parte está la I glesia; santo papa, cardenales, obispos, etc. y a la otra banda, emperador, reyes y caballeros. ${ }^{46}$

Q uiero llamar la atención sobre estas jerarquías. En un estudio previo,47 había emitido la importancia de esta descripción y la había vinculado con los grabados sobre las jerarquías eclesiástica y temporal que aparecen en la Rhetorica Christiana de fray D iego de Valadés (Perugia, I539).48 Las jerarquías valadesianas las relacioné con las teorías arbóreo-enciclopédicas de Ramón Llull. Señalé como posible fuente iconográfica de Valadés la enciclopedia del

45. "LoS 30 segmentos en que se divide aluden a la edad de Cristo, a la vez que son expresión de la multiplicación del número io que es la cifra del hombre, con el tres de la Trinidad." $\mathrm{M}$ arie-M adeleine de la Garanderie, "Aspects de l'exégèse de Charles de Bovelles", Acta conventus $\mathrm{N}$ eo-latini T orontensis, p. 283.

46. Fray Toribio de Benavente M otolinía, M emoriales o Libro de las cosas de la $N$ ueva España y de los naturales de ella, cap. xxxv, p. Io3.

47. Aún sin publicar: "M nemosyne novohispánica", M éxico, 1999.

48. C fr. fray D iego de Valadés, Rhetorica Christiana: la jerarquía eclesiástica, pars quarta, entre pp. 176 y 177, y la jerarquía temporal, pars quarta, entre pp. I80-I8I. 
Iulista Bernardo de Lavinheta, Practica compendiosaque, ${ }^{49}$ puesto que en ella encontramos una jerarquía arbórea que hace alusión a una organización temporal-monárquica y eclesiástica del universo.

En el brazo derecho se colocaron los cardenales, los patriarcas, los obispos, los abades, los priores, los sacerdotes, y los clérigos; en el izquierdo se colocaron los emperadores y los reyes, los duques, los condes, los barones, los militares, los burgueses y los campesinos. Los ramos son los sacramentos y los mandamientos de la ley, las hojas son los cánones y las leyes, que el papa suministra a su régimen. Las flores son los catorce artículos de la fe, acerca de los cuales arriba se ha hecho mención..$^{\circ}$

Estas jerarquías responden a la idea neoplatónica que hemos venido delineando en el sentido amoroso que busca alcanzar el máximo bien como expresión de la belleza dentro de la vida religiosa íntima y social del hombre:

...y tiene a toda la cristiandad en ella misma [jerarquía], junta, ligada y unida... el sector de los clérigos suministra la vida espiritual a los laicos... así el poder terrenal es de acuerdo al espiritual y a ella se subordina. ${ }^{\text {st }}$

C ada elemento de la jerarquía tiene la obligación de transmitir el máximo bienestar, orden, amor y belleza que recibe de C risto a los subsiguientes niveles.52

49. Edición facsimilar de E. W. Platzeck: Bernard de Lavinheta, Explanatio compendiosaque applicatio artis Raymundi Lulli, H ildesheim, Gerstenberg Verlag, 1977.

50. "In dextra bracchia ponuntur in primis cardinales, patriarche, episcopiabbates, priores, sacerdotes simplices et clerici in sinistra ponuntur imperatores et reges, duces, comites, barones, milites, burguenses et rurales. Rami sunt sacramenta et mandata legis: folia sunt canones et leges, quibus papa indiget ad suum regimen. Flores aut sunt xIV articuli fidei, de quibus supradictum est." Bernard de Lavinheta, Explanatio compendiosaque applicatio artis Raymundi Lulli, f. 75V-r.

5I. "...et tenet totam christianitatem sibi copulatam, colligata et unitam... pars clericalis parti laicali influitvitam spiritualem... ita potestas terrena est propter spiritualem et ad illam ordinatur." I bidem, f. 73 r.

52. "Papa influentiam et potestatem immediate recipit de Christo et ad inferioreset particulares ordine quodam per viam concordantie trasmittit, ideo in tertio regno, qui non obedierit principi, morte moriatur, necessaria est ergo talis summa unio et concordantia esse non potest absque summa capitis potestate... et hoc consistit in quadam concordantia et quae est in uno et pluribus." Ibidem, f. $73 \mathrm{~V}$. 
C reo que esta asociación, tanto iconográfica como literaria resulta, hasta ahora, válida. Pero también hay otra asociación literaria que nos salta al camino y que complementa en gran medida la fuente luliana: la concepción sobre las jerarquías de Dionisio el Areopagita, ${ }^{53}$ que de hecho tal vez Llull tomó como ejemplo, y cuyas obras fueron también editadas y estudiadas por el círculo humanista francés en torno a Lefèvre d'Etaples. 54 La diferencia es que Llull suele agregar la jerarquía-árbol temporal que se refiere a la organización social bajo un sistema monárquico. Creo que Bouvelles combina ambas teorías (la lulista y la seudodionisiana), 55 y que en Lavinheta se continúa esta visión dentro de su Explanatio. ${ }^{56}$

Veamos: dentro de la concepción de Dionisio la jerarquía representa el orden sagrado (distintos niveles en los que se colocan los obispos, ministros y sacerdotes), cuya actividad (purificación, iluminación y perfección) acerca al catecúmeno al encuentro con D ios.57 D e ahí que el objetivo principal de la jerarquía sea llevar las almas a restablecer su unidad con Dios, ${ }^{88}$ donde el deseo por lo bello se traduzca en una ascensión hacia la fuente de luz divina.59 Sólo a través de la ayuda de la jerarquía el alma asciende y, así, es posible para cada uno tener la oportunidad de compartir con Dios lo que es bello, sabio y bueno. ${ }^{60}$

Pienso que la importancia o el valor de esta visión jerárquica se vio reforzada en Bouvelles, con el orden del mundo, tanto eclesiástico como temporal que exponía Llull, por medio de una expresión más sencilla: los modelos de narrativa luliana se dirigían a un público mayor ${ }^{6 \mathrm{I}}$ y se aplicaban

53. Pseudo-Dionysius, The Complete Works (tr. Colm Luibheid y Paul Rorem), Londres, The Classics of W estern Spirituality, 1987.

54. A. Renaudet, H umanisme et Renaissance, p. 206.

55. C onsidero que el tema iconográfico se desarrolla más por la vía lulista, ya que además se hace tratamiento de la jerarquía temporal (gobernantes) que no aparece en D ionisio, y que se retoma en Lavinheta y algunos misioneros franciscanos.

56. Para determinar las relaciones entre Lavinheta, Bouvelles y Lefèvre, véase en general a J. M. Victor, "The Revival of Lullism at Paris, I499-1516", en Renaissance Q uaterly, núm. 4, vol. XXVIII, I975, pp. 504-534.

57. C fr. P. Dionysius, The Ecclesiastical H ierarchy, The Complete W orks, 536 D ., p. 248.

58. Ibidem, 376 A, pp. 198.

59. Ibidem, 372 B y 373 D, pp. 196 y 198.

6o. Ibidem, 373 A, p. 197 .

6I. Para las formas narrativas en Llull, véase Lola Badia, T eoría y práctica de la literatura en Ramón Llull, Barcelona, Q uaderns Crema, 1992. 
a una organización social más real y concreta de su tiempo. Es sabido que la novela lulista, el Libre de meravelles, influyó a Bouvelles de manera decisiva. ${ }^{62}$ Félix es un personaje joven que se maravilla ante el universo creado por D ios y de este universo se resalta el carácter jerárquico en el que reside su orden y, por lo tanto, su armonía. Así expone acerca del orden social que:

- H ijo - dijo el ermitaño a Félix-, Dios ha ordenado que en este mundo hay reyes para que mantengan la justicia, y que haya prelados para conservar nuestra fe, y que debajo del dominio de los reyes haya condes, duques, marqueses, caballeros, ciudadanos, mercaderes, labradores, y así de los demás oficios; y lo mesmo ha dispuesto en el estado eclesiástico, pues ha ordenado que bajo la orden de los prelados estén los clérigos, frailes y demás eclesiásticos, divididos en varios oficios, para que por orden puedan y deban mantener la santidad del mundo, para que en él $D$ ios sea alabado, conocido y amado. ${ }^{63}$

$\mathrm{N}$ os volvemos a topar con este concepto que hizo a Llull predilecto entre los renacentistas: la armonía del mundo basada en las jerarquías, cuyo equilibrio y cumplimiento de las funciones de cada elemento garantizaba la paz cristiana bajo la cual se organizaba la sociedad, y a través de ellas se debía "recordar, amar, entender y memorar a D ios". ${ }^{64}$

Ahora bien, aún no podemos figurarnos con mayor exactitud, ni por las descripciones sobre la iconografía jerárquica de Valadés y de M otolinía, cómo pudo haber funcionado más escrupulosamente la integración del indígena-catecúmeno a la comunidad cristiana. Es decir, sabemos que los misioneros suministraban los sacramentos, enseñaban los principales pilares del catecismo: hacían que el indígena consumiera símbolos reales, imágenes

62. J. Gaya, "Réminiscences Iuliennes dans I'anthropologie de Bovelles", Charles de Bovelles et son cinquième centenaire (I479-1979), p. I49.

63. "Fill-dix lo ermità a Felix-, D éus ordonà que en aquestmón sien reys per tenir dretura, e sien prelats per conservar nostra fe; e sots reys són comtes, duchs e marqueses, cavallers et burgueses, mercaders e pageses, e axí de los altres officics; e axò mateix ha ordonat sots prelats, hon ha diverces officis de clergues, qui per ordre deven mantenir santedat, veritat, en lo món, a lausar, conoxèr e amar Déu." Ramon Llull, Libre de meravelles, Els N ostres Classics, vol. 4, líneas 8-17, p. 63.

64. "Fill, los hòmens hordonadament han v senys corporals ab què usen de les coses corporals, per les quals poden haver orda en membrar, entendre e amar les coses speritals, e haver virtuts e desamar vicis." I bi dem, vol. 4, líneas 24-28, pp. 6I-62. 
litúrgicas, para convertirse al cristianismo. La manera de suministrarlos por los evangelizadores es lo que nos queda por proponer: tratar de describir el camino desde su plano teórico al práctico. ¿Podríamos aventurarnos a describir el método?

Creo que es posible proponer un esbozo de tal metodología misionera, y ésta puede ser explicada por el lulismo-seudodionisiano de Charles de Bouvelles, que pudo haber estado presente en la mente de algunos misioneros en el $\mathrm{N}$ uevo Mundo.

\section{V}

Remembra Blanquerna les divinals virtuts e volc per aquelles contemplar D eu en lo Pare nostre, e les virtuts, el Pater noster volc metre en sa memoria, enteniment e volentat.

Ramon Llull, Art de Contemplació, Libre de Blanquerna, cap. vII, p. 462.

El misionero tuvo la obligación moral de iniciar al indígena en la vida cristiana. Algo que constantemente se repitió en los catecismos y crónicas de evangelización ${ }^{65}$ fue la enseñanza de la oración dominical, es decir la oración que Cristo les enseñó a los hombres. El pater noster alude al sacrificio del $\mathrm{H}$ ijo de Dios y, con ello, posibilita la redención de la humanidad que encuentra su significado en el "danos hoy nuestro pan de cada día"; tanto el pan como el vino aluden simbólicamente al cuerpo y a la sangre de C risto. ${ }^{66}$ En el Libre de meravelles la enseñanza de la oración dominical es "el medio por el cual las virtudes de D ios influyen su similitud en las virtudes del hombre", de manera tal que cuando el hombre "contempla a Dios, su bondad tiene similitud con la de Dios, en cuanto el hombre es bueno por la oración que hace contemplando a Dios". ${ }^{67}$ Llull expone la manera tradicional cris-

65. Por ejemplo, M otolinía, M emoriales o Libro de las cosas, cap. 46, p. I43; cap. 50 , p. 156. 66. N uevo T estamento, Lucas II, 2C-4; M ateo 6, 9b-13.

67. "O ració és mijà per llo qual les virtuts de D éu influexen lur semblança en les virtuts de hom, sa semblança en ço que aquell hom és bo per la oració que fa contemplant D éu; e con la oració és gran, adonchs la granea de Déu hi influèx se semblança en ço que fa aquella oració gran en bonea, duració, poder, e axí de totes. Açò mateix fa eternitat, que la oració fa durar influent sa semblança; e açò mateix se pot dir de poder, de saviessa..." Ramon Llull, Libre de 
tiana que se empleaba para enseñar el pater noster en el catecismo: la división de la oración en peticiones (varían de siete a diez) y su consiguiente explicación o ejemplificación. ${ }^{68}$

Si bien es cierto que la tradición de dividir el pater noster en peticiones data desde el medievo, ${ }^{69}$ también lo es que Bouvelles le da un giro nuevo. D urante el medievo, las formas o figurae más acostumbradas para exponer el pater fueron los árboles, las ruedas y las escalas. ${ }^{70}$ Sin embargo, hasta ahora no sé de ningún modelo similar al que planteó Bouvelles.

I. Pontífices-Padre nuestro que estás en los cielos

2. Sacerdotes-Santificado sea tu nombre

3. Diáconos-V énganos tu reino

4. Subdiáconos-H ágase tu voluntad en la tierra, así como en el cielo

5. M inistros-D anos hoy nuestro pan de cada día

6. M onjes-Perdona nuestras ofensas

7. Plebeyos-Así como nosotros perdonamos a los que nos ofenden

8. Energúmenos-N o nos dejes caer en tentación

9. Catecúmenos-M as líbranos del mal

Io. Al mismo tiempo todos los grados de la jerarquía eclesiástica-Amén.

Para Bouvelles, el alma internamente se eleva hacia Dios a través de las peticiones del pater: cada una se liga con un nivel de la jerarquía, es decir cada petición es suministrada por uno de sus integrantes específicamente. La oración, así ejercitada, concilia al alma con D ios. M ás allá, el deseo de la oración nace puramente del impulso amoroso neoplatónico, que, como producto final, genera la concordia que ratifica el deseo y establecimiento del orden. Se construye y se confirma, así, la jerarquía armónica del universo. Ante esta exposición, podemos suponer que no solamente estamos frente a una expli-

meravelles, Els N ostres Classics, vol. 4, líneas 25-II, pp. 206-207.

68. Ramon Llull, Art de Contemplació, Libre de Blanquerna, vol. 9, cap. 7, pp. 462-466.

69. Para este tema: Antonio Raspanti, Filosofia, teologia, religione, Palermo, Edi O rfes, I991; Klaus Bernhard Schnurr, $\mathrm{H}$ ören und $\mathrm{H}$ andeln. Lateinische Aus egungen des $\mathrm{V}$ aterunsers in der Alten Kirche bis zum 5. Jahrhundert, Friburgo, H erder, 1985.

70. Para ejemplos de este tipo de figurae y su funcionamiento véase $U$ Irich Rehm, Bebi ldete Vaterunsererklärungen des M ittelalters, Baden-Baden, Verlag Valentin Köerner, Saecula Spiritualia 28, 1944. 
cación doctrinal de la oración, según el método medieval, sino ante la integración del sistema luliano-dionisiano. Esto significa que el pater descansa sobre un sistema ascensional (asurreccional), ${ }^{71}$ que eleva al hombre, a través del ejercicio de su voluntad-amor, hacia Dios para colmarse en su unificación y restitución. ${ }^{72}$

Lo importante es contemplar que, dentro de este tipo de catequesis, el pater noster se re-presentaba. Es decir, durante el medievo se enseñaba bajo un contexto retórico que implicaba el uso dramático-teatral con fines edificantes (la retórica se dividía en inventio, dispositio, actio, memoria).73 Bajo la actio de la retórica cabe entender la mise en scène del pater noster, que tenía como fin denunciar los vicios y los pecados, a cambio de incitar al ejercicio de las virtudes: el auto exponía, así, los beneficios del pater noster. ${ }^{74}$ Resulta así que en el medievo la representación de las siete peticiones se llevaba a cabo por medio de la recitación de sermones en la personificación alegórica de los siete pecados capitales.75 En Bouvelles, por ejemplo, la exégesis del pater noster se lleva a cabo por cada ministro de la iglesia ligado a una petición. Asimismo, cada uno posee un cáracter teatral, puesto que cada uno es puesto en escena asumiendo un papel actoral: "Ellos rezan,... ellos demandan..."76

7I. Para la explicación del término, cfr. P. M agnard, “L'idéal du Sage dans le D e Sapiente de C harles de Bouvelles", Charles de Bovelles et son cinquième centenaire, p. Io7.

72. "M ente deum nitida docet hic orare libellus/ O ret sectatorum qui cupit esse dei./ Si penetrar brevis (ut dicunt) oratio celos: $\mathrm{N}$ il opus est vocum plurima congeries./ $\mathrm{N}$ on labiis igitur presso sed corde tonantem/ $\mathrm{N} \mathrm{ec}$ longa studeas conciliare prece." Carolus Bovillus, D ominica oratio, cit. por G aranderie, "Aspects de l'exégèse de C harles de Bovelles", Acta conventus N eo-latini Torontensis, p. 288.

73. Remito al lector al teatro inglés, en el que tenemos la primera documentación sobre la representación dramática del pater noster en la ciudad de York en 1378 . C fr. Karl Young, "T he Records of the York Play of the Pater noster", Speculum, 7 (1932), pp. 540-546.

74. "Primo quod ad causam fundacionis dicte fraternitatis, sciendum est quod postquam quidum ludus de utilitate 0 racionis $D$ ominicae compositus, in quo ludo quam plura vicia et peccata reprobantur et virtutes commendantur... U tinam iste ludus in civitate ista gubernaretur in salutem animarum et in consolacionem civium et vicinorum." D ocumento enviado por la liga de York al consejo del Rey en Chancery, 21 de enero de 1389 , Karl Young, "The Records of the York Play of the Pater noster", Speculum, 7 (1932), p. 54I.

75. Cfr. la colección de sermones, M irk's Festial y el M s. de la Royal Collection i8 B, XXIII, del British M useum; cfr. Alexandra Johnston, "The Plays of the Religious Guilds of York: The Creed Play and the Pater N oster Play", Speculum, vol. 50 (1975), p. 79.

76. C arolus Bovillus, D ominica oratio, cit. por Garanderie, "Aspects de l'exégèse de Charles de Bovelles", Acta conventus N eo-latini T orontensis, p. 29I. 
Es decir que las jerarquías eclesiásticas no participan como categorías abstractas, sino que tienen una existencia concreta. Los personajes entran en escena y finalmente "todos juntos cantan en concordia sus voces el Amén", que desde "la tierra se eleva hasta los cielos y los coros de los ángeles, como si fuera un eco". ${ }^{77}$ Estas características de mise en scène, nos hacen pensar en que los personajes de la literatura luliana, como un ermitaño y un niño - Félix, que es introducido a la vida religiosa-, ofrecían una manera concreta, más allá aun de ser representaciones alegóricas, de introducir al "catecúmeno" a la vida religiosa. Esto presenta posibles asociaciones con el carácter teatral de evangelización novohispana.

Es verdad, sabemos o suponemos al menos que los lienzos y las pinturas que utilizaban los misioneros para representar la doctrina eran explicados no sólo oralmente por los misioneros evangelizadores, sino que les agregaban cierto carácter dramático tan caro a nuestra cultura prehispánica. ${ }^{78}$ Efectivamente, dentro de las relaciones del hombre con el cosmos y los dioses en la cultura prehispánica, la práctica del ritual se volvió una interacción dramática de los mexicas hacia sus dioses, y a través de ellos al cosmos mismo. El contenido narrativo iba acompañado de música, danza, diálogos y una rica escenografía. ${ }^{79}$ Lamentablemente, no poseemos más información detallada sobre la explicación del pater dentro de la enseñanza catequética: simplemente, M otolinía nos habla de la representación pictórica de las dos jerarquías (temporal-monarquía y eclesiástica-sacerdocio) y la enseñanza de la oración dominical.

Insisto: ipudieron las jerarquías relacionarse con la enseñanza de la oración dominical y, en dado caso, pudo haber sido el texto de Bouvelles un posible modelo lulista-dionisiano para ello?

Para responder la pregunta, me atrevo a pensar que la representación iconográfica de la jerarquía eclesiástica (que aparece en Llull, Bouvelles, Lavinheta, Valadés y M otolinía), implicaba tal vez una recitación sermonal con carácter dramático donde, si seguimos a Bouvelles, se recitaba el pater. Ambos, la procesión del Corpus y la oración dominical, que quiero pensar

77. Garanderie, "Aspects de l'exégèse de Charles de Bovelles", Acta conventus N eo-latini Torontensis, p. 29I.

78. Sobre el teatro misionero, véase Alfonso Reyes, "T eatro misionario", en H istoria crítica de la literatura hispanoamericana. Época colonial, vol. I, pp. 332-336.

79. M arylin Ravice Ekdahl, Early Colonial D rama in M exico: From T zompantli to Golgotha, p. 9. 
que se enseñaba en la procesión mediante una mise en scène ante las jerarquías, confirmaban el sentido primordial que se quería suministrar a los indígenas dentro del proceso de conversión: el misterio eucarístico del cuerpo de Cristo hecho ritual social, a través del que toda la sociedad novohispana se integraba. ${ }^{80} \mathrm{C}$ ada sector de la sociedad encontraba su lugar y su participación en la fiesta del Corpus y, con esto, los indígenas eran incorporados como piezas clave de una estructura armónica del universo cristiano, que en su restitutio planteaba la regeneración, la restauración de una nueva armonía, la construcción de un nuevo orden socio-religioso.

No es casual que la introducción del Corpus (I520) en la Nueva España haya servido para garantizar la estabilidad que en esa década había sido violentada con la conquista. El Corpus fungió como ese elemento esperanzador de restitutio renacentista después del tiempo catastrófico: fue un espejo social, una imagen del universo en gestación donde las comunidades indígenas fueron iniciadas a la celebración de manera pacífica. ${ }^{8 \mathrm{I}}$

Digo esto porque una rápida revisión sobre el análisis del Corpus en is39 en T laxacala nos deja entrever que, en la representación de la Conquista de Jerusalén, todos (indígenas y españoles) se someten al rey de España y reciben el bautismo para garantizar la cristiandad universal. ${ }^{82}$ La batalla final no se gana por las armas, sino por la intervención divina de san M iguel arcángel..$^{83}$ Es decir, por la vía pacífica de la palabra divina se encuentra solución al conflicto, sin necesidad del uso de la fuerza y la imposición que implican la guerra y el ejercicio del poder para erradicar posturas contrarias a la fe. M ás claramente: el uso de la retórica puesta en escena (verbo y gesto) expone un valor sin igual que conlleva la conciliación y concordia vía pacífica: la persuasión en presencia del Santo Sacramento, del papa y su corte. ${ }^{84}$

8o. C fr. P. D ionysius, Eclesiastical H ierarchy. The Complete W orks, 536 D, p. 248: "T he holy sacraments bring about purification, illumination, perfection. The deacons form the order which purifies. The Priests constitute the order which gives illumination. And the $\mathrm{H}$ ierarchs, living in conformity with God, make up the order which perfects."

8I. Serge G ruzinski, "La fête-D ieu à M exico au temps de la N ouvelle-Espagne", en Le corps de Dieu en fêtes, p. I39.

82. Cfr. fray Toribio de Benavente M otolinía, M emoriales, cap. 35, pp. io6-II2.

83. Ibidem, cap. 35, p. in2.

84. Cfr. Berta Ares Q ueija, “U ne représentation théatrale dans une fête-D ieu colonniale. ' $M$ aures et $C$ hrétiens' en N ouvelle-Espagne" (I539), Le corps de D ieu en fêtes, pp. I59-I74, I68I69. 
Creo así que podemos reconocer más que una iconografía lulistaseudodionisiana neoplatónica en las jerarquías, lo que el uso de ella implica en este contexto de evangelización: la búsqueda de la fundación de un edificio social armónico, mediante la función correcta de los miembros de las jerarquías, revela el deseo nacido del amor (como hemos revisado en Ficino) que busca restablecer el orden del mundo basado en la concordia social. Reconocer la temática amorosa, vista bajo estos parámetros, me lleva al rescate de algo que nuestra memoria histórica se ha encargado de sumir en el olvido: el effuerzo de los misioneros por el empleo de un sistema retórico de conversión, por persuasión y no por imposición.

Bajo esto hay un transfondo político claro: los franciscanos advierten que los gobernantes deben someterse a un modelo jerárquico pać́fico de evangelización; asimismo, exigen muchos de ellos reconocer en el indígena los mismos derechos que los españoles ante el emperador y $D$ ios. ${ }^{85}$

Sólo así se logrará integrar un edificio armónico social, donde la voluntad del hombre funde la restauración religiosa con modelos más evangélicos; de lo contrario, ese orden puede resquebrajarse.

La unidad divina es causa de toda unidad, la paz divina de toda paz y la concordia de toda concordia. También la ruptura con Dios es discordia: toda diferencia y discordia con él es causa de ruptura interna y recíproca, de división, de discordia. ${ }^{86}$

Lo último puede ocurrir por la corrupción de la virtus en el gobernante que, al apartarse del ejercicio del impulso amoroso que lo dirige, tanto hacia la fuente de toda belleza como del bien, se deja arrastrar por la ambición corrompiendo el alma. En el caso de los reyes - cabezas de la república- es motivo de desequilibrio, ocasión del desorden y de la destrucción de la arquitectura de la jerarquía, aspectos que contiene en su haber contradictorio la influencia de Saturno de la que le hablaba Bouvelles a Cisneros. D e manera tal que:

La causa por que han muerto y destruydo tantas y tales e tan infinito número de ánimas los christianos, ha sido solamente por tener por su fin el oro y henchirse

85. Berta Ares Q ueija, “U ne représentation théatrale dans une fête-D ieu colonniale. 'M aures et Chrétiens' en N ouvelle-Espagne" (I539), Le corps de Dieu en fêtes, p. I7I.

86. "Divina unitas omnis unitatis: pax pacis et concordia est causa. D ivina quoque lis dissidentia et discordia: omnis et proprie et mutue litis dividii dissidentie et discordie est causa." Caroli Bovillus, De sapiente, 0 pera, cap. XLvirI. 
de riquezas en muy breves días, e subir a estados muy altos e sin proporción de sus personas (conviene a saber) por la insaciable cudicia e ambición que han tenido, que ha sido mayor que el mundo ser pudo, por ser aquellas tierras tan felices e tan ricas. ${ }^{87}$

Fray Bartolomé de las $C$ asas bien señala que la destrucción del orden armónico se debió a que los conquistadores, encomenderos, burócratas gobernantes (jerarquía temporal) desobedecieron al emperador-papa: viciados "por el ansia de poder, de puestos más altos, de ambición del oro", lejos de tratar de comprender al indígena, lo eliminan y practican la represión. ${ }^{88} \mathrm{La}$ imposición y la violencia como flagrantes formas de poder e impunidad destruyen con sus vicios el orden de la jerarquía eclesiástica que convierte por disuasión retórica, y no por la violencia utilizada por los dirigentes de la jerarquía temporal. La degeneración de la virtus fomenta la imposición del interés individual (avaricia, sed de poder) en contra de la procuración del bien común, violentando, así, lo que es diferente: al que se pretende desaparecer antes que aceptarlo e integrarlo al orden del universo. ${ }^{89}$ Bajo la destrucción se encubre el uso de la imposición violenta a cambio del uso de la retórica.

Por principio, es decir debido a la función que la sociedad les ha encomendado a los gobernantes de resguardar el orden, son los que llevan mayor responsabilidad como organismos que son de la jerarquía regidora y reguladora de la sociedad; si su regencia falla y se olvida el ejercicio recto de las virtudes del alma humana, esa estructura rompe su musicalidad armónica y sobrevienen el caos, el desamor y, por lo tanto, el apartamiento de lo divino en el hombre: el hombre nacido bajo el planeta de Saturno sucumbe ante las influencias negativas si no ejerce su voluntad de amor hacia lo bello, lo divino, lo virtuoso, lo justo y lo bueno.

En este sentido, la crisis de la estructura social que denunciarán los misioneros será, efectivamente, la de los gobernantes. Veremos a los

87. Fray Bartolomé de las Casas, Brevís ma relación dela destrucción de indias, f. aV v.

88. Ibidem, f. aV v.

89. "[indios]... gentes tan humildes, tan pacientes y tan fáciles a subjetarlas, a las quales no han tenido más respecto ni dellas han hecho más cuenta ni estima... Y esta es una muy notoria e averiguada verdad, que todos aunque sean los tiranos e matadores la saben e la confiessan, que nunca los yndios de todas las yndias hizieron mal alguno a los christianos, antes los tuvieron venidos por el cielo, hasta que primero muchas veces ovieron recebido dellos, o sus vezinos, muchos males, robos, muertes, violencias y vexaciones dellos mesmos." I bidem, f. aV v. 
misioneros cronistas quejarse amargamente de esto, de la ambición de poder y dinero que ha corrompido a la burocracia española, que si bien no ha llegado a tocar al emperador, pareciera ser una advertencia, en la que se señala el peligro de perder las virtudes de una actitud recta y de un gobierno recto, ${ }^{9 \circ} \mathrm{y}$ cuya denuncia por la palabra no debe dejarse esperar.

\section{Conclusión}

...y gritan la $\mathrm{H}$ istoria. La gritan para que no se duerma, para que la memoria no muera, para que viva gritan nuestros muertos... Q ue la dignidad nunca pierda la memoria, que si la pierde, muere.

Comunicado del EZLN a A. Jahangir, La Jornada, 2I de julio de 1999 .

La conversión que plantea el lulismo neoplatonizante y su seguidor Bouvelles se caracteriza por eso: por demostrar mediante todo ejercicio retórico, desde verbal hasta gestual, las verdades de la religión cristiana, suministradas y veladas por los integrantes de las jerarquías. En este caso, el cristianismo sólo incorpora otras religiones, mediante el ejercicio de la seducción retórica, es decir de un acercamiento a través del ejercicio de la palabra, traducida en sermón-diálogo y llevada a la escenificación. Restitutio y renovatio del universo son expresión directa de una práctica amorosa que abre la posibilidad de digerir una visión europea no impuesta, sino suministrada por medio de ciertos ideales religioso-misioneros que, gracias a su sentido de reforma interna avenida de la corriente del cardenal Cisneros, se encaminan a plantear formas de pacificación y concordia.

Para terminar, la idea medular que quiero transmitir es la de rescatar una memoria social basada en la experiencia del amor neoplatónico: darle así un giro opuesto, pero complementario (como juego de opuestos neoplatónico y saturniano), a la visión violenta de la conquista que hemos denunciado. D escubrir sus causas, más allá de los efectos que nos son tan conocidos, para no olvidar y, con esto, recordar que precisamente esta última se produjo por la

90. Aúno a esta temática fray G erónimo de M endieta, $\mathrm{H}$ istoria edesiástica indiana (facsimilar), za. ed., M éxico, Porrúa, I97I. 
corrupción virtuosa que sufrió la estructura jerárquica temporal, desembocando así en la ruptura del ejercicio retórico propuesto por la jerarquía eclesiástica (en este caso, a cargo de las órdenes regulares). El presente sigue siendo parte de esa ruptura histórica que, si bien se "da noticia a los reyes de ella", no ha sido escuchada, y por lo tanto somos aún esquirlas de un vago recuerdo de la armonía: astillas que, en vez de renovar parte de nuestra experiencia histórica dialogada, la monologan.

Atravieso la inefable paz divina (como dice el Areopagita) no más adverso a los ángeles 0 a Dios, mejor a colaborar con ellos en la obra divina en la medida de nuestras fuerzas. Sin la paz divina no los recordamos, no se unen con nosotros mismos, ni con los otros, ni con los ángeles, ni con Dios. ${ }^{91}$

La incapacidad que tenemos de ejercer un diálogo se da, no porque no tengamos esa experiencia dentro de nuestra historia social, sino porque precisamente la jerarquía temporal ha desoído, peor aún olvidado, la lección de la memoria histórica.

Y esto nos da una razón vital del porqué de la importancia de los estudios del siglo xvi: al reconocer la incursión del neoplatonismo y su aspiración de renovación y restitución, por medio del ejercicio de modelos retóricos (lulismo, por ejemplo) como posibles venas que nutrieron el sistema de pensamiento de los misioneros, podremos ser capaces de ejercer al go que ya hemos vivido en nuestra memoria colectiva e histórica y, aún más allá de eso, desarrollarlo, madurar lo que el olvido colectivo nos ha truncado: la retórica que es la cara opuesta de la moneda, que distante de ejercer la violencia provocada por la corrupción, el vicio, el abuso y la imposición (como lo denunciaron algunos misioneros que fraguaron nuestra identidad, querámoslo o no), propone la integración del otro en el orden del universo, por medio de la palabra actuada:

- Además has de saber, hijo- dijo el ermitaño-, que D ios ha ordenado y dispuesto que haya tanto poder en el Sumo Pontífice, en los cardenales, en los reli-

9I. "Per divinam indeffabilem pacem (ut D ivus areopagita testatur) neque amplius adversum angelos aut deum: belligerare discimus. Sed cum ipsis ut ait, divina potius per viribus perage mus. Sine divina autem pace: neque ipsi nobiscum neque in ivicem, neque cum angelis, neque cum D eo conruimus inferimur unimur." C. Bovillus, D e sapiente, 0 pera, cap. xLVIII. 
64

giosos, y en todos los eclesiásticos, que por su poder y saber puedan ordenar y disponer que los infieles se reduzcan al camino de la verdad y la salvación; y lo mesmo pueden los reyes y los príncipes a quienes $D$ ios ha dado tanto poder, que pueden mantener la justicia, la verdad y la religión en la tierra; lo que muchos no ejecutan, porque aunque tienen el poder y la sabiduría, les falta voluntad; y por esto de día en día se multiplica el desorden y se disminuye el orden..$^{22}$ \&

92. "-Fill - dix lo ermità a Felix - , D éus ha ordonat com stia tant de poder en l'apostoli, e en los cardenals, e en los prelats, e en los religiosos e clergues, que qui per poder, que qui per saviesa, pusquen ordonar com los infaels venguen a via de veritat; e açó mateix se segueix dels reys e dels prínceps; hon D éus ha ordonat tant de poder, que poden tenir dretura en terra; mas det all volentat a poder e a saviessa, e per aço muntiplica desordonança e minua ordonança." R. Llull, Libre de meravelles, Els N ostres Classics, vol. 4, líneas I2-23, p. 64. 


\section{Bibliografía}

Fuentes primarias

Benavente, M otolinía, fray T oribio de, M emoriales o Libro de las cosas de la N ueva España y de los naturales de ella (ed. Edmundo O ' G orman), M éxico, U niversidad N acional Autónoma de M éxico, i97ı.

Bovillus, Carolus, D ominica oratio tertrinis ecclesiasticae hierarchiae ordinibus particulatim attributa et facili explanata commentaria, Amiens, Jean Petit, I5II.

,--- 0 pera omnia, París, isıo.

- - , Proverbiorum vulgarium libri tres, París, I53I.

Casas, fray Bartolomé de las, Brevís ma relación de la destrucción de Indias (edición facsimilar, intr. M anuel Ballesteros), M adrid, Fundación U niversitaria Española, I977.

Ficino, M arsilio, Commentary on Plato's Symposium on Love (tr. Sears J ayne), D allas, Spring Publications, 1985 .

- - - 0 pera omnia, Basilea, 1576 (edición facsimilar de 0 . Kristeller), 2 vols., T urín, Bottega d'Erasmo, 1962.

Lavinheta, Bernard de, Explanatio compendiosaque applicatio artis Raymundi Lulli (ed. ErhardW olfram Platzeck), H ildesheim, G erstenberg V erlag, 1977.

Llull, Ramon, Libre de meravelles, Els N ostres Classics (ed. Salvador Galmés), vol. 4, Barcelona, Barcino, I934.

- - - Libre de Blanquerna, Obres Originals del Illuminat Doctor M estre Ramon Lull (eds. Salvador Galmés, M iquel Ferrà), vol. 9, Palma de M allorca, Comissió Editora Lulliana, I9I4.

M endieta, fray Gerónimo de, H istoria eclesástica indiana (edición facsimilar), za. ed., M éxico, Porrúa, I97I.

M irandola, Pico della, D e hominis dignitate, H eptaplus, D e ente et uno (ed. E. G arin), Florencia, Vallecchi Editore, 1992.

0 pera sopra la scala mistica di Giacobe, Florencia, I5I2.

Pseudo-D ionysus, The CompleteW orks (tr. Colm Luibheid Paul y Rorem), Londres.

Valadés, fray D iego de, Rhetorica christiana, Perugia, I579.

Fuentes secundarias

Adeva, Ildefonso y Carmen J. Alejos, "Fuentes de inspiración de la Regla cristiana breve de fr. Juan de Zumárraga, O FM ", en Archivvum Franciscanum H istoricum, 85 (1992), pp. 77-98.

Allen, M ichel J. B., N uptial Arithmetic. M arsilio Ficino's Commentary on the Fatal $\mathrm{N}$ umber in Book VIII of Plato's Republic, Berkeley, U niversity of C alifornia Press, I994.

Ares $Q$ ueija, Berta, "U ne représentation théatrale dans une fête-D ieu colonniale. 'M aures et Chrétiens' en N ouvelle-Espagne" (I539), Le corps de D ieu en fêtes, pp. I59-174.

Badia, Lola, T eoría y práctica dela literatura en Ramón Llull, Barcelona, Q uaderns Crema, 1992.

Bataillon, M arcel, Erasmo y España. Estudios sobre la historia espiritual del s glo xvı (tr. Antonio Alatorre), 2a. ed., M éxico, Fondo de Cultura Económica, 1966. 
Carreras y Artau, H istoria de la filosofía española de los siglos XIII al XV, 2 vols., M adrid, Real Academia de Ciencias Exactas, Físicas y N aturales, 1943.

Cassirer, E., Individuum und Kosmos in der Philosophie der Renaissance, Leipzig-Berlín, B. G. T eubner, 1927.

Charles de Bovelles et son cinquième centenaire (1479-1979). Actes du Colloque International tenè a N oyon, París, G uy T rénadiel, 1982.

Féstugiere, Jean, La philosophie de l'amour de Marsile Ficin et son influence sur la littérature française au xvie siècle, París, Librarie Philosophique J. V rin, i94I.

Garanderie, $M$ arie-M adeleine de la, "Aspects de l'exégèse de Charles de Bovelles", Acta conventus $\mathrm{N}$ eo-latini Torontensis, Binghampton- $\mathrm{N}$ ueva York, M edieval and Renaissance Texts and Studies, I99I, pp. 28I-292.

Garin, Eugenio, Giovanni Pico della M irandola. Vita e dottrina, Florencia, Felice le M onnier, 1937.

--- , I talian H umanism. Philosophy and Civic Life in the Renaissance (tr. Peter M unz), O xford, Basil Blackwell, 1965.

- - - , La cultura filosofica del Rinascimento Italiano, Florencia, G. C. Sansoni Editore, I96I.

Gaya, J., "Réminiscences luliennes dans I'anthropologie de Bovelles", en Charles de Bovelles et son cinquième centenaire (1479-1979), pp. I43-156.

Gruzinski, Serge, "La fête-D ieu à M exico au temps de la N ouvelle-Espagné", en Le corps de Dieu en fêtes (ed. Antoninette M olinié), París, C erf, 1996, pp. 137-158.

H eck, C hristian, L'échelle céleste dans l'art du M oyen Age, París, Flammarion, 1997.

Johnston, Alexandra, "The Plays of the Religious Guilds of York: The Creed Play and the Pater N oster Play", Speculum, vol. 50 (1975), pp. 55-90.

Klibansky, Raymond, Erwin Panofsky, Fritz Saxl, Saturno y la melancolía (tr. M aría Luisa Balseiro), M adrid, Alianza, 1989.

K risteller, O ., Philosophy of M arsilio Ficino, N ueva York, Columbia U niversity Press, 1943.

M agnard, P., "L'idéal du Sage dans le De Sapiente de Charles de Bouvelles", en Charles de Bovelles et son cinqui ème centenaire (I479-1979), pp. IO2-IO8.

M acherel, Claude, "Corpus christi, cosmos et societé", en Le corps de Dieu en fêtes (ed. Antoninette M olinié), París, Cerf, 1996, pp. 47-64.

M omigliano, Arnaldo, "From the Pagan to the Christian Sybil: Prophecy as $\mathrm{H}$ istory of Religion", The U ses of G reek and Latin (eds. A. C. Dionisotti, A. G rafton, J. Kraye), Londres, The W arburg Institute, 1988, pp. 3-17.

Raspanti, Antonio, Filosofia, teologia, religione, Palermo, Edi O rfes, I99I.

Ravice Ekdahl, M arylin, Early Colonial Drama in M exico: From Tzompantli to Golgotha, W ashington, I970.

Rehm, U Irich, Bebildete V aterunsererklärungen des M ittelalters, Baden-Baden, V erlag V alentin Köerner, Saecula Spiritualia 28, 1944.

Renaudet, Augustin, H umanisme et Renaissance, Génova, Libraire E. D roz, I958.

- - , Préréforme et Humanisme à Paris (I494-I5I7), 2a. ed., Génova, Slatkine Reprints, 1953.

Reyes, Alfonso, "T eatro misionario", en Historia crítica de la literatura hispanoamericana. É poca colonial, vol. I, pp. 332-336. 
Schnurr, Klaus Bernhard, $\mathrm{H}$ ören und $\mathrm{H}$ andeln. Lateini sche Aus egungen des Vaterunsers in der Alten Kirche bis zum 5 Jahrhundert, Friburgo, $\mathrm{H}$ erder, 1985.

Vasoli, Cesare, Civitas mundi. Studi sulla cultura de cinquecento, Roma, Edizione Storia e Letteratura, 1996.

- - - , "L'hermétisme dans I'O raculum de Giovanni N essi", en Cahiers de L'H ermétisme Présence d'H ermès T rismégi ste, París, Albin M ichel, 1988, pp. I53-166.

Victor, J. M., "Charles de Bouvelles and Nicholas de Pax: Two Sixteenth-Century Biographies of Ramon Lull", Traditio, xxxiI (1976), pp. 313-345.

--- , Charles de Bovelles (1479-1553). An Intellectual Biography, Génova, Libraire D rosz, I978.

Young, Karl, "T he Records of the York Play of the Pater N oster", Speculum, 7 (1932), pp. 540-546.

W alker, D. P., The Ancient Theology, Londres, D uckworth, 1972.

W einstein, D onald, Savonarola and Florence. Prophecy and Patriotism in the Renaissance, Princeton, Princeton U niversity Press, 1970. 